\title{
Clinical Study \\ High Prevalence of Antinuclear Antibodies in Children with Thyroid Autoimmunity
}

\author{
Maria Segni, ${ }^{1}$ Ida Pucarelli, ${ }^{1}$ Simona Truglia, ${ }^{2}$ Ilaria Turriziani, ${ }^{1}$ \\ Chiara Serafinelli, ${ }^{1}$ and Fabrizio Conti ${ }^{2}$ \\ ${ }^{1}$ Department of Pediatrics, Endocrinology Unit, “Sapienza” University of Rome, Via Regina Elena 324, 00161 Rome, Italy \\ ${ }^{2}$ Department of Internal Medicine and Medical Specialties, Rheumatology, "Sapienza” University of Rome, Rome, Italy
}

Correspondence should be addressed to Maria Segni; m.segni@mclink.it

Received 8 December 2013; Accepted 8 January 2014; Published 24 February 2014

Academic Editor: Marvin J. Fritzler

Copyright (C) 2014 Maria Segni et al. This is an open access article distributed under the Creative Commons Attribution License, which permits unrestricted use, distribution, and reproduction in any medium, provided the original work is properly cited.

\begin{abstract}
Background. Antinuclear antibodies (ANA) are a hallmark of many autoimmune diseases and can be detected many years before disease onset. Autoimmune thyroid diseases (AITD) are frequently associated with other organ- and non-organ-specific autoimmune disorders. Objectives. To assess the prevalence of ANA in pediatric patients with AITD and their clinical correlations. Methods. Ninety-three consecutive pediatric patients with AITD were enrolled (86 children with chronic lymphocytic thyroiditis and 7 with Graves' disease). ANA, anti-double DNA (anti-dsDNA) antibodies, anti-extractable nuclear antigen (anti-ENA), anticyclic citrullinated peptide antibodies (anti-CCP), and rheumatoid factor (RF) was obtained. Signs and symptoms potentially related to rheumatic diseases in children were investigated by a questionnaire. Results. ANA positivity was found in 66/93 children (71\%), anti-ENA in 4/93 (4.3\%), anti-dsDNA in 1/93 (1.1\%), RF in 3/93 (3.2\%), and anti-CCP in none. No significant differences were found between the ANA-positive and ANA-negative groups with respect to age, sex, L-thyroxine treatment, or prevalence of other autoimmune diseases. Overall, parental autoimmunity was found in $23 \%$. Conclusions. ANA positivity was demonstrated in $71 \%$ of children with AITD. ANA positivity was not related to overt immune-rheumatic diseases. However, because the positivity of ANA can occur even many years before the onset of systemic autoimmune diseases, prospective studies are warranted.
\end{abstract}

\section{Introduction}

Antinuclear antibodies (ANA) are a marker of several autoimmune diseases including autoimmune thyroid disease (AITD) and Systemic Lupus Erythematosus (SLE) and they can be detected many years before disease onset [1-5]. ANA positivity can also be found in patients with malignant or infectious diseases as well as in healthy subjects [2-5].

The AITD, Graves' disease (GD), and chronic lymphocytic thyroiditis (CLT) are organ-specific autoimmune disorders that are defined by lymphocytic infiltration of the thyroid [6] and autoantibodies against thyroid antigens [i.e., thyroid peroxidase antibody (TPOAb), thyroglobulin antibody (TgAb), and anti-TSH-receptor antibody (TRAb)] [7]. AITD is frequently associated with other organ and nonorgan-specific autoimmune disorders [8-10]. This association has been also reported in juvenile forms of chronic arthritis and SLE $[11,12]$. ANA prevalence up to $45 \%$ has been reported in adult patients with AITD $[13,14]$. To the best of our knowledge, so far, only one study analyzed ANA positivity in children with AITD [15]. We investigated the prevalence of serum ANA in pediatric patients with AITD and their association with signs and symptoms related to immunerheumatic diseases.

\section{Patients and Methods}

We studied 93 consecutive children (86 patients with CLT and 7 with GD, 76 females) referred for AITD to the Pediatric Endocrinology Unit of "Sapienza" University in Rome. CLT was defined on the basis of the presence of thyroid autoantibodies more than two times the upper normal value (nv) ([TPOAb nv $<20 \mathrm{IU} / \mathrm{mL}]$ and/or TgAb 
$[\mathrm{nv}<50 \mathrm{IU} / \mathrm{mL}])$ and thyroid ultrasound evaluation showing reduced echogenicity compatible with thyroiditis, regardless of thyroid function. GD was defined by clinical and biochemical hyperthyroidism and by positivity for TRAb.

Written informed consent was obtained from parents. This study was approved by the ethical committee of our institution.

The enrolled patients underwent a complete physical examination and the clinical and laboratory data were collected in a standardized form, which includes demographics, past medical history with date of diagnosis, comorbidities, and previous and concomitant treatments. All children and parents were interviewed according to a questionnaire seeking signs and symptoms related to rheumatic diseases in children. The questionnaire took into account the following signs and symptoms: joint pain, joint swelling, back pain, morning stiffness, asthenia, Raynaud's phenomenon, xerostomia, xerophthalmia, pleuritis, and pericarditis. Children with signs and/or symptoms suggestive of immunerheumatic diseases were examined by a rheumatologist (FC).

Patients underwent peripheral blood sample collection and sera were stored at $-20^{\circ} \mathrm{C}$ until being assayed.

Free T3, free T4, TSH, TPOAb, and TgAb serum levels were determined in all patients and TRAb were determined in presence of hyperthyroidism. FT3 and FT4 were determined by RIA and TSH (upper normal value $3.5 \mu \mathrm{U} / \mathrm{mL}$ ) was determined by immunoradiometric assay (all by Byk Sangtec Diagnostica, Dietzbach, Germany). TRAb were detected by radioreceptor assay (Radim, Angleur, Belgium) and TPOAb and TgAb by immunoradiometric assay (ICN Pharmaceutical Inc., Costa Mesa, CA).

ANA were detected by indirect immunofluorescence assay (IIFA) on HEp-2 cells (ANA Nova LIte TM HEp2, INOVA Diagnostics Inc., San Diego, CA 92131, USA). Anti-double DNA antibodies (anti-dsDNA) were investigated by Crithidia luciliae immunofluorescence test (CLIFT) (A. Menarini Diagnostics, 50131 Florence, Italy). ANA were considered positive at a titer $\geq 1: 80$, anti-dsDNA at a titer $\geq$ $1: 10$. Immunofluorscence intensity ranged from + to ++++ . Serum antibodies against extractable nuclear antigen (antiENA screening and in the case of ENA positivity: Sm, RNP, SS-A, SS-B, Scl-70, Jo-1) were determined by ELISA (QUANTA Lite ENA 6, INOVA Diagnostics Inc., San Diego, CA 92131, USA). In addition, anti-cyclic citrullinated peptide antibodies (anti-CCP) and rheumatoid factor (RF) were determined. Anti-CCP were determined by fluoroenzymeimmunoassay (EliACCP), using immunoCAP 100 analyzer (Phadia AB, 75002 Uppsala, Sweden) and RF was determined by nephelometry using BN2 automate (N Latex RF kit, Siemens Healthcare Diagnostics Products, Marburg 35037, Germany).

\section{Statistics}

Statistical calculations were performed using SPSS for Windows Version 17 (SPSS, Chicago, IL, USA). Data were expressed as mean and standard deviation for continuous data. Chi-square or Fisher's exact test was carried out when appropriate. $P$ values $<0.05$ were considered statistically significant.

\section{Results}

Clinical and laboratory features of the enrolled patients are reported in Table $1(\mathrm{a})$. ANA positivity was found in $66 / 93$ children (71\%), anti-ENA was found in 4/93 (4.3\%), anti-dsDNA antibodies were found in $1 / 93(1.1 \%)$, RF was detectable in 3/93 (3.2\%), and anti-CCP were found in none. ENA-specific autoantibodies were determined in 3 out of 4 anti-ENA-positive patients, 1 had anti-RNP positive, 1 had anti-Jo-1, and 1 was negative for specific autoantibodies. The ANA pattern was homogeneous in 61/66 (92.4\%), coarse/fine speckled in $4 / 66(6 \%)$, and nucleolar in $2 / 66(3 \%)$. The IIFA intensity was +++ in $23 / 66(34.8 \%)$, ++ in $24 / 66$ (36.3\%), and + in 19/66 (28.7\%) cases.

Among the 93 children with AITD, 20 (21\%) had at least one other autoimmune disease: 9 with celiac disease (CD), 2 with autoimmune gastritis (AG), 4 with type 1 diabetes mellitus (type $1 \mathrm{DM}$ ), 2 with alopecia, 2 with vitiligo, and 1 with autoimmune thrombocytopenia. We found that $3 / 7$ (43\%) of children with GD presented with one other autoimmune disease (1 CD, 1 type DM, and $1 \mathrm{AG}$ ), versus 17/86 (20\%) with CLT (8 CD, 1 AG, 3 type $1 \mathrm{DM}, 2$ alopecia, 2 vitiligo, and 1 autoimmune thrombocytopenia). The difference in the frequency of autoimmune disease associated with CLT versus GD was not significant.

Clinical and laboratory features of ANA-positive and ANA-negative patients are compared in Table 1(b). No significant differences were found between the ANA-positive and ANA-negative groups with respect to age, sex, L-thyroxine treatment, TSH, TPOAb, and TgAb levels, or presence of other autoimmune diseases in them and in their parents. Associated autoimmune diseases in ANA-positive and ANAnegative children and their parents are reported in Table 2. Hereby ANA-positive children did not differ for the frequency of additional autoimmune disease, but there was a higher percentage of parental autoimmunity in ANAnegative patients, however, without significance.

Signs and symptoms as investigated by questionnaire are detailed in Table 3. No significant differences were found between ANA-positive and ANA-negative children with AITD.

Children with persistent joint pain were referred to a rheumatologist (FC). Children with Raynaud's phenomenon underwent capillaroscopy. No evidence of SLE, RA, or other systemic autoimmune diseases was found.

\section{Discussion}

AITD is a common autoimmune disease and it is frequently associated with other organ and non-organ-specific autoimmune disorders [8-10]. A variable ANA prevalence up to $45 \%$ has been reported in AITD adult patients $[13,14]$.

ANA can also be detected in different autoimmune disorders (i.e., SLE, Sjogren's syndrome, progressive systemic sclerosis, mixed connective-tissue disease, juvenile idiopathic 
TABLE 1: (a) Clinical and laboratory features of the patients at inclusion. (b) Clinical and laboratory features of ANA-positive and ANAnegative children.

(a)

\begin{tabular}{lc}
\hline Characteristic & Patients $(N=93)$ \\
\hline F/M & $76 / 17$ \\
CLT $(N)$ & 86 \\
GD $(N)$ & 7 \\
Age at diagnosis (mean years \pm SD) & $10.2 \pm 3.9$ \\
Age at sampling (mean years \pm SD) & $12.1 \pm 4.86$ \\
Duration of disease (mean years \pm SD) & $2.79 \pm 3.67$ \\
CLT on LT4 treatment $(N / \%)$ & $47 / 86(54.6 \%)$ \\
TSH $(\mu \mathrm{IU} / \mathrm{mL} \pm \mathrm{SD})$ & $2.8 \pm 1.8$ \\
TPOAb $(\mathrm{IU} / \mathrm{mL} \pm \mathrm{SD})$ & $819 \pm 908$ \\
TgAb $(\mathrm{IU} / \mathrm{mL} \pm \mathrm{SD})$ & $512 \pm 605$ \\
Associated autoimmune disease in children $(N / \%)$ & $20 / 93(21 \%)$ \\
Associated autoimmune disease in CLT $(N / \%)$ & $17 / 86(20 \%)$ \\
Associated autoimmune disease in GD $(N / \%)$ & $3 / 7(43 \%)$ \\
Autoimmune disease in parents $(N / \%)$ & $43 / 186(23 \%)$ \\
\hline
\end{tabular}

(b)

\begin{tabular}{lccc}
\hline Patients & ANA positive $(N=66)$ & ANA negative $(N=27)$ & $P$ \\
\hline F/M & $56 / 10$ & $20 / 7$ & 0.7 \\
\hline CLT $(N / \%)$ & $62(72 \%)$ & $3(43 \%)$ & 0.7 \\
GD $(N \%)$ & $4(57 \%)$ & $9.9 \pm 4.2$ & 0.61 \\
Age at diagnosis (mean years \pm SD) & $10.4 \pm 3.8$ & $11.4 \pm 4.4$ & 0.32 \\
Age at sampling (mean years \pm SD) & $12.4 \pm 4.8$ & $2.48 \pm 1.86$ & 0.2 \\
TSH $(\mu \mathrm{IU} / \mathrm{mL} \pm \mathrm{SD})$ & $3.01 \pm 1.77$ & $614 \pm 803$ & 0.61 \\
TPOAb $(\mathrm{IU} / \mathrm{mL} \pm \mathrm{SD})$ & $903 \pm 941$ & $494 \pm 666$ & 0.85 \\
TgAb $(\mathrm{IU} / \mathrm{mL} \pm \mathrm{SD})$ & $519 \pm 593$ & $16 / 27(66 \%)$ & 0.99 \\
LT4 therapy $(\mathrm{CLT})(N / \%)$ & $31 / 62(50 \%)$ & & \\
\hline
\end{tabular}

F/M: females/males; CLT: chronic lymphocytic thyroiditis; GD: graves' disease; TSH: thyroid stimulating hormone; TPOAb: thyroid peroxidase antibodies; TgAb: thyroglobulin antibodies; LT4: L-thyroxine.

arthritis, primary autoimmune cholangitis, and autoimmune hepatitis) as well as in infections $(2,4)$. In particular, ANA can be detected in over ninety percent of patients with SLE, a multifactorial autoimmune disease, involving genetic and environmental factors, characterized by a wide range of autoantibodies and clinical manifestations [4, 16-25].

ANA can be also found in healthy people [2]. A recent cross-sectional analysis of 4754 individuals older than 12 years showed a prevalence of ANA of $13.8 \%$ [26]. A similar prevalence of $12.6 \%$ was reported in healthy children, with higher titers found between 5 and 10 years of age [27]. To our knowledge, only one previous study investigated ANA prevalence in children with AITD. The authors, using a cutoff of 1:40 for ANA IIFA on HEp-2 cells, demonstrated an incidence of ANA positivity significantly higher in patients with untreated GD (71\%) than in CLT (33\%) [15]. In addition, ANA positivity was identified as a predictive factor for poor response to antithyroid drugs in GD. In our study, CLT represented $92 \%$ of total enrolled patients versus 36\% in the previous study. Since we analyzed GD regardless of treatment and we included only 7 children affected with GD, we were not able to correlate GD activity with ANA positivity. In CLT patients, we did not find any difference in L-thyroxine treatment between ANA-positive and ANA-negative children. In contrast, a correlation between increased ANA levels and reduced thyroid volumes was reported in adult patients affected by vitiligo and AITD [28].

To detect serum ANA, we used the same method of Inamo and Harada [15], IIFA on HEp-2 cells, that is considered the most reliable method to search ANA [2, 29]. Using a higher cut-off value of $1: 80$, we found detectable ANA in $71 \%$ of children with AITD and the IIFA homogeneous pattern was detected in $92 \%$ of cases. Titers and pattern of ANA have been proposed to be a critical parameter for discriminating ANA, a homogeneous pattern being suggestive of rheumatic diseases [30]. A nuclear fine speckled pattern was reported in ANA-positive healthy children in $77 \%$ of cases [27].

We did not find any significant difference in ANApositive and ANA-negative group with respect to age, sex, LT4 treatment, TSH, TPOAb and TgAb levels, and prevalence of other autoimmune diseases in the children or in the parents. No differences were detected investigating 
TABLE 2: Associated autoimmune diseases in ANA-positive and ANA-negative children with AITD and in their parents.

\begin{tabular}{|c|c|c|c|}
\hline Patients & ANA positive $(N=66)$ & ANA negative $(N=27)$ & $P$ \\
\hline Associated autoimmune diseases $(N / \%)$ & $14 / 66(21 \%)$ & $6 / 27(22 \%)$ & 0.87 \\
\hline Celiac disease $(N)$ & 6 & 3 & \\
\hline Type 1 DM $(N)$ & 2 & 2 & \\
\hline Autoimmune gastritis $(N)$ & 2 & 0 & \\
\hline Vitiligo $(N)$ & 2 & 0 & \\
\hline Alopecia $(N)$ & 1 & 1 & \\
\hline Autoimmune thrombocytopenia $(N)$ & 1 & 0 & \\
\hline Parents & 66 mothers, 66 fathers & 27 mothers, 27 fathers & \\
\hline Autoimmune diseases in parents $(N / \%)$ & $27 / 132(20.4 \%)$ & $16 / 54(29.6 \%)$ & 0.24 \\
\hline Autoimmune diseases in mothers $(N)$ & 18 & 10 & \\
\hline $\operatorname{AITD}(N)$ & 14 & 10 & \\
\hline $\operatorname{SLE}(N)$ & 1 & 0 & \\
\hline Sjogren's syndrome $(N)$ & 1 & 0 & \\
\hline Autoimmune thrombocytopenia (N) & 1 & 0 & \\
\hline Autoimmune diseases in fathers $(N)$ & 9 & 6 & \\
\hline $\operatorname{AITD}(N)$ & 8 & 4 & \\
\hline Vitiligo $(N)$ & 1 & 1 & \\
\hline Rheumatoid arthritis $(N)$ & 0 & 1 & \\
\hline
\end{tabular}

Type 1 DM: type 1 diabetes mellitus; AITD: autoimmune thyroid disease; SLE: systemic lupus erythematosus.

TABLE 3: Positive answers at questionnaire in ANA-positive and ANA-negative children with AITD.

\begin{tabular}{lccc}
\hline Question & $\begin{array}{c}\text { ANA positive } \\
(N=66)\end{array}$ & $\begin{array}{c}\text { ANA negative } \\
(N=27)\end{array}$ & $P$ \\
\hline Joint pain & $12(18 \%)$ & $5(18 \%)$ & 0.87 \\
\hline Joint swelling & $0(0 \%)$ & $0(0 \%)$ & - \\
Morning stiffness & $1(1.5 \%)$ & $0(0 \%)$ & - \\
Back pain & $1(1.5 \%)$ & $1(3.7 \%)$ & - \\
Asthenia & $14(21 \%)$ & $4(14 \%)$ & 0.47 \\
Raynaud's & $3(4.5 \%)$ & $1(3.7 \%)$ & 0.63 \\
Xerostomia & $3(4.5 \%)$ & $1(3.7 \%)$ & 0.63 \\
Xerophthalmia & $3(4.5 \%)$ & $1(3.7 \%)$ & 0.63 \\
Pleuritis & 0 & 0 & - \\
Pericarditis & 0 & 0 & - \\
\hline
\end{tabular}

signs and symptoms of systemic diseases between ANApositive and ANA-negative group. Altogether, joint pain was referred by $19 \%$ of patients, asthenia was referred by $19 \%$, and Raynaud's phenomenon was present in $4.3 \%$, as well as xerostomia and xerophtalmia. Because of the fact that hypothyroidism itself can cause symptoms as asthenia, we confirmed symptoms when children were euthyroid. Torok and Arkachaisri [31] in children and adolescents referred to a rheumatological center for ANA positivity and investigated for AITD, found arthralgias and fatigue more frequently in ANA-positive/antithyroid antibodies-negative subjects. The prevalence of positive antithyroid antibodies in this study was $30 \%$ versus $3-4 \%$ in general pediatric population [32], and hypothyroidism was found in $14 \%$. It may suggest that to screen for AITD may be worthwhile in apparently healthy children with ANA positivity.

The clinical and biological meaning of ANA is still debated $[29,33,34]$. It has been speculated that a defect in the mechanisms involved in the engulfment of dead cell with inappropriate clearance of self-nucleic acids can cause autoimmune diseases. A deficiency of clearance of apoptotic cells is considered one of the causes of SLE and may underlie autoimmunity itself [35-37]. Activation of the innate and acquired immune response, which can be induced by infection, inflammation, or tissue injury, may impact on the development of autoimmunity in the thyroid [38, 39]. We can speculate that such a high prevalence of ANA in juvenile AITD may be read as a link to the involvement of self nucleic acids in the development of AITD.

An important point of our study is the observation of parental autoimmunity in up to $30 \%$ with only slightly lower percentage $(20 \%)$ in ANA-positive children. Whether this reflects (epi-)genetic heritability or a shared familial environment triggering autoimmunity in parents and children needs to be investigated in prospective family studies.

In conclusion, although we analyzed a limited number of cases, our study demonstrated ANA positivity in over $70 \%$ of children with AITD. ANA positivity at the time of the study was not related to overt immune-rheumatic diseases.

In our opinion, the finding of ANA positivity in children and adolescents affected by AITD needs a careful reevaluation: it can be interpreted as a manifestation of "activated autoimmunity" without clinical relevance at the time of the study. However, because the positivity of ANA and other nonorgan-specific autoantibodies can occur even many years 
before the onset of systemic autoimmune diseases [5, 40,41], we think that prospective studies are warranted, especially in subjects positive for anti-dsDNA and anti-ENA.

\section{Conflict of Interests}

The authors declare that there is no conflict of interests regarding the publication of this paper.

\section{References}

[1] R. H. White and D. L. Robbins, "Clinical significance and interpretation of antinuclear antibodies," Western Journal of Medicine, vol. 147, no. 2, pp. 210-213, 1987.

[2] N. Agmon-Levin, J. Damoiseaux, C. Kallenberg et al., "International recommendations for the assessment of autoantibodies to cellular antigens referred to as anti-nuclear antibodies," Annals of the Rheumatic Diseases, vol. 73, pp. 17-23, 2013.

[3] A. P. Weetman, "Non-thyroid autoantibodies inauitoimmune thyroid disease," Best Practice and Research, vol. 19, no. 1, pp. 17-32, 2005.

[4] F. Conti, C. Alessandri, D. Bompane et al., "Autoantibody profile in systemic lupus erythematosus with psychiatric manifestations: a role for anti-endothelial-cell antibodies," Arthritis Research \& Therapy, vol. 6, no. 4, pp. R366-R372, 2004.

[5] M. R. Arbuckle, M. T. McClain, M. V. Rubertone et al., "Development of autoantibodies before the clinical onset of systemic lupus erythematosus," New England Journal of Medicine, vol. 349, no. 16, pp. 1526-1533, 2003.

[6] F. G. A. Delemarre, P. J. Simons, and H. A. Drexhage, "Histomorphological aspects of the development of thyroid autoimmune diseases: consequences for our understanding of endocrine ophthalmopathy," Thyroid, vol. 6, no. 4, pp. 369-377, 1996.

[7] B. Rapoport and S. M. McLachlan, "Thyroid autoimmunity," Journal of Clinical Investigation, vol. 108, no. 9, pp. 1253-1259, 2001.

[8] G. S. Eisenbarth and P. A. Gottlieb, "Medical progress: autoimmune polyendocrine syndromes," New England Journal of Medicine, vol. 350, no. 20, pp. 2068-2079, 2004.

[9] K. Boelaert, P. R. Newby, M. J. Simmonds et al., "Prevalence and relative risk of other autoimmune diseases in subjects with autoimmune thyroid disease," American Journal of Medicine, vol. 123, no. 2, pp. 183.el-183.e9, 2010.

[10] I. Lazurova and K. Benhatchi, "Autoimmune Thyroid diseases and nonorgan-specific autoimmunity," Polskie Archiwum Medycyny Wewnętrznej, vol. 122, supplement 1, pp. 55-59, 2012.

[11] D. Mihailova, R. Grigorova, B. Vassileva et al., "Autoimmune thyroid disorders in juvenile chronic arthritis and systemic lupus erythematosus," Advances in Experimental Medicine and Biology, vol. 455, pp. 55-60, 1999.

[12] S. Stagi, T. Giani, G. Simonini, and F. Falcini, "Thyroid function, autoimmune thyroiditis and coeliac disease in juvenile idiopathic arthritis," Rheumatology, vol. 44, no. 4, pp. 517-520, 2005.

[13] M. G. Tektonidou, M. Anapliotou, P. Vlachoyiannopoulos, and H. M. Moutsopoulos, "Presence of systemic autoimmune disorders in patients with autoimmune thyroid diseases," Annals of the Rheumatic Diseases, vol. 63, no. 9, pp. 1159-1161, 2004.
[14] I. Lazúrová, K. Benhatchi, J. Rovenský et al., "Autoimmune thyroid disease and autoimmune rheumatic disorders: a twosided analysis," Annals of the New York Academy of Sciences, vol. 1173, pp. 211-216, 2009.

[15] Y. Inamo and K. Harada, "Antinuclear antibody positivity in pediatric patients with autoimmune thyroid disease," Journal of Rheumatology, vol. 24, no. 3, pp. 576-578, 1997.

[16] R. Priori, E. Medda, F. Conti et al., "Familial autoimmunity as a risk factor for systemic lupus erythematosus and vice versa: a case-control study," Lupus, vol. 12, no. 10, pp. 735-740, 2003.

[17] G. Valesini, C. Alessandri, D. Celestino, and F. Conti, "Antiendothelial antibodies and neuropsychiatric systemic lupus erythematosus," Annals of the New York Academy of Sciences, vol. 1069, pp. 118-128, 2006.

[18] T. Colasanti, A. Maselli, F. Conti et al., "Autoantibodies to estrogen receptor $\alpha$ interfere with T lymphocyte homeostasis and are associated with disease activity in systemic lupus erythematosus," Arthritis and Rheumatism, vol. 64, no. 3, pp. 778-787, 2012.

[19] P. Margutti, M. Sorice, F. Conti et al., "Screening of an endothelial cDNA library identifies the C-terminal region of Nedd5 as a novel autoantigen in systemic lupus erythematosus with psychiatric manifestations," Arthritis Research \& Therapy, vol. 7, no. 4, pp. R896-R903, 2005.

[20] G. C. Tsokos, "Mechanisms of disease: systemic lupus erythematosus," New England Journal of Medicine, vol. 365, no. 22, pp. 2110-2121, 2011.

[21] F. Conti, F. R. Spinelli, C. Alessandri, and G. Valesini, “Toll-like receptors and lupus nephritis," Clinical Reviews in Allergy and Immunology, vol. 40, no. 3, pp. 192-198, 2011.

[22] C. Perricone, C. Ciccacci, F. Ceccarelli et al., "TRAF3IP2 gene and systemic lupus erythematosus: association with disease susceptibility and pericarditis development," Immunogenetics, vol. 65, pp. 703-709, 2013.

[23] F. Conti, C. Alessandri, C. Perricone et al., "Neurocognitive dysfunction in systemic lupus erythematosus: association with antiphospholipid antibodies, disease activity and chronic damage," PLoS ONE, vol. 7, no. 3, Article ID e33824, 2012.

[24] F. Conti, F. Ceccarelli, L. Massaro et al., "Evaluation of the patient acceptable symptom state (PASS) in Italian patients affected by systemic lupus erythematosus: association with disease activity indices," PLoS ONE, vol. 8, Article ID e73517, 2013.

[25] C. Iannuccelli, F. R. Spinelli, M. P. Guzzo et al., "Fatigue and widespread pain in Systemic Lupus Erythematosus and Sjogren's Syndrome: symptoms of the inflammatory disease or associated Fibromyalgia?" Clinical and Experimental Rheumatology, vol. 30, pp. S117-S121, 2012.

[26] M. Satoh, E. K. L. Chan, L. A. Ho et al., "Prevalence and sociodemographic correlates of antinuclear antibodies in United States," Arthritis \& Rheumatism, vol. 64, pp. 2319-2327, 2012.

[27] M. O. Esteves Hilário, C. A. Len, S. Campos Roja, M. T. Terreri, G. Almeida, and L. E. Coelho Andrade, "Frequency of antinuclear antibodies in healthy children and adolescents," Clinical Pediatrics, vol. 43, no. 7, pp. 637-642, 2004.

[28] G. Zettinig, A. Tanew, G. Fischer, W. Mayr, R. Dudczak, and M. Weissel, "Autoimmune diseases in vitiligo: do anti-nuclear antibodies decrease thyroid volume?" Clinical and Experimental Immunology, vol. 131, no. 2, pp. 347-354, 2003.

[29] D. H. Solomon, A. J. Kavanaugh, P. H. Schur et al., "Evidencebased guidelines for the use of immunologic tests: antinuclear 
antibody testing," Arthritis and Rheumatism, vol. 47, no. 4, pp. 434-444, 2002.

[30] H. A. Mariz, E. I. Sato, S. H. Barbosa, S. H. Rodrigues, A. Dellavance, and L. E. C. Andrade, "Pattern on the antinuclear antibody-HEp-2 test is a critical parameter for discriminating antinuclear antibody-positive healthy individuals and patients with autoimmune rheumatic diseases," Arthritis and Rheumatism, vol. 63, no. 1, pp. 191-200, 2011.

[31] K. S. Torok and T. Arkachaisri, "Autoimmune thyroiditis in antinuclear antibody positive children without rheumatologic disease," Pediatric Rheumatology, vol. 8, article 15, 2010.

[32] A. Loviselli, L. Grasso, M. Songini et al., "The sardinian autoimmunity study: 3. Studies on circulating antithyroid antibodies in sardinian schoolchildren: relationship to goiter prevalence and thyroid function," Thyroid, vol. 11, no. 9, pp. 849-857, 2001.

[33] P. L. Meroni and P. H. Schur, "ANA screening: an old test with new recommendations," Annals of the Rheumatic Diseases, vol. 69, no. 8, pp. 1420-1422, 2010.

[34] D. S. Pisetsky, "Antinuclear antibodies in healthy people: the tip of autoimmunity's iceberg?" Arthritis Research and Therapy, vol. 13, no. 2, article 109, 2011.

[35] T. Colasanti, C. Alessandri, A. Capozzi et al., "Autoantibodies specific to a peptide of $\beta 2$-glycoprotein I cross-react with TLR4 inducing a pro-inflammatory phenotype in endothelial cells and monocytes," Blood, vol. 120, pp. 3360-3370, 2012.

[36] S. Nagata, R. Hanayama, and K. Kawane, "Autoimmunity and the clearance of dead cells," Cell, vol. 140, no. 5, pp. 619-630, 2010.

[37] U. S. Gaipl, A. Kuhn, A. Sheriff et al., "Clearance of apoptotic cells in human SLE," Current Directions in Autoimmunity, vol. 9, pp. 173-187, 2006.

[38] A. Kawashima, K. Tanigawa, T. Akama et al., "Fragments of cenomic DNA released by injured cells activate innate immunity and suppress endocrine function in the thyroid," Endocrinology, vol. 152, no. 4, pp. 1702-1712, 2011.

[39] A. Kawashima, K. Tanigawa, T. Akama, A. Yoshihara, N. Ishii, and K. Suzuki, "Innate immune activation and thyroid autoimmunity," Journal of Clinical Endocrinology and Metabolism, vol. 96, no. 12, pp. 3661-3671, 2011.

[40] H. Kokkonen, M. Mullazehi, E. Berglin et al., "Antibodies of IgG, IgA and IgM isotypes against cyclic citrullinated peptide precede the development of rheumatoid arthritis," Arthritis Research and Therapy, vol. 13, no. 1, article R13, 2011.

[41] P. Moinzadeh, S. I. Nihtyanova, K. Howell, V. H. Ong, and C. P. Denton, "Inpact of hallmark autoantibody reactivity on early diagnosis in scleroderma," Clinical Reviews in Allergy \& Immunology, vol. 43, pp. 249-255, 2012. 


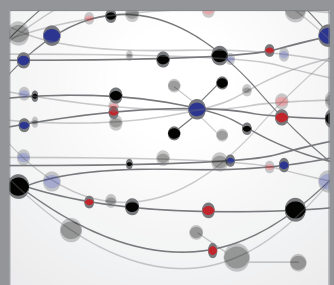

The Scientific World Journal
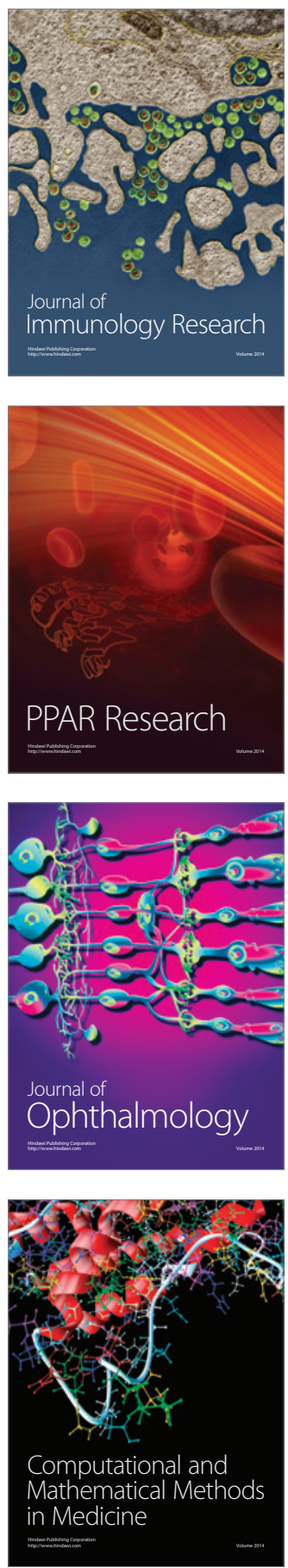

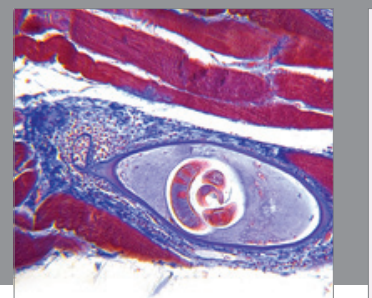

Gastroenterology

Research and Practice
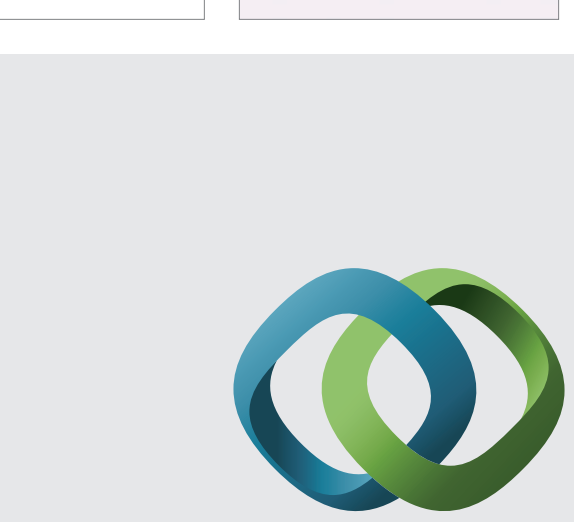

\section{Hindawi}

Submit your manuscripts at

http://www.hindawi.com
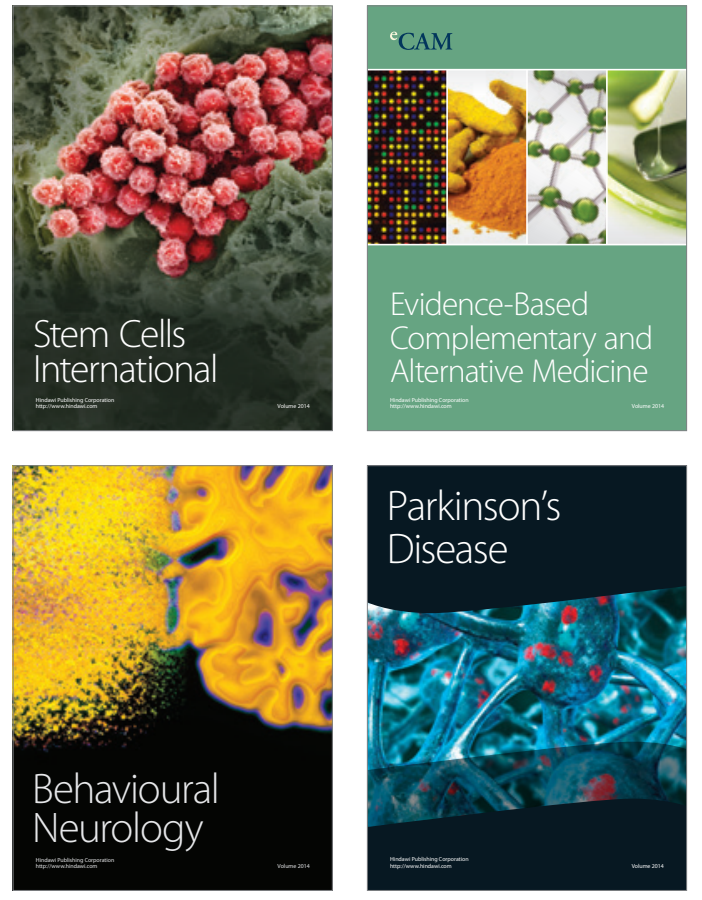
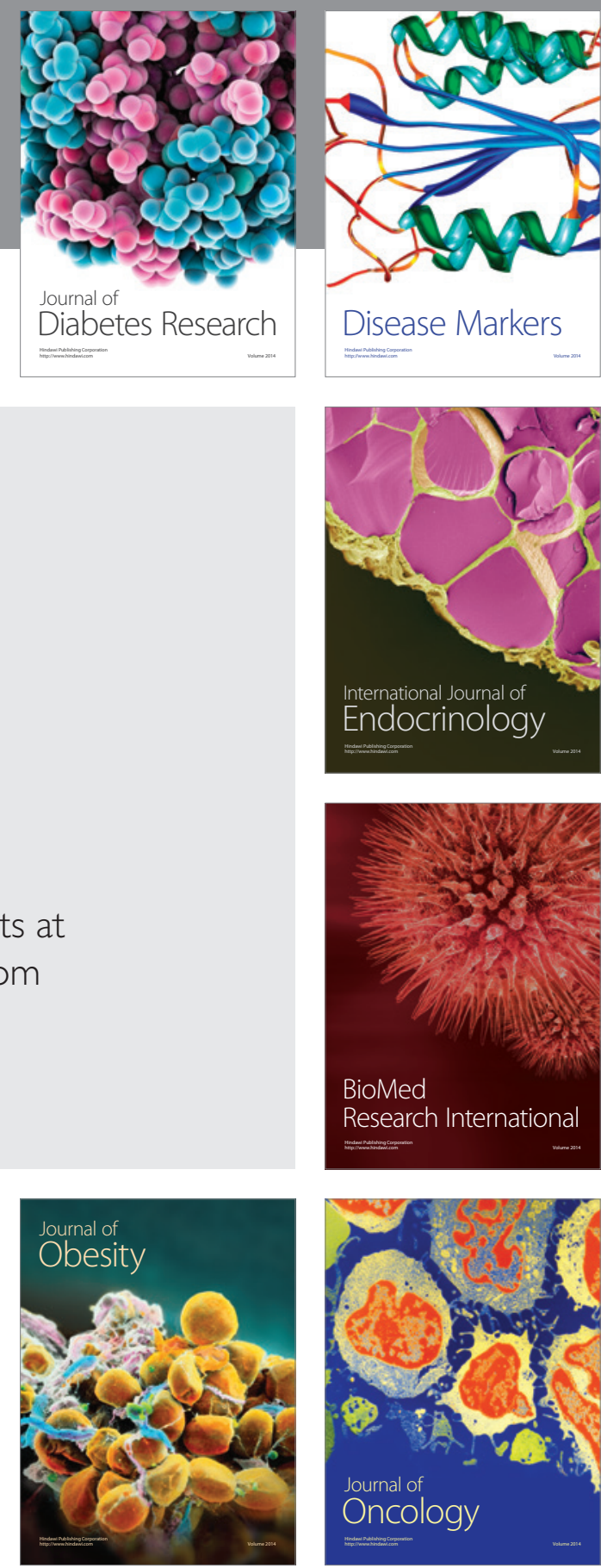

Disease Markers
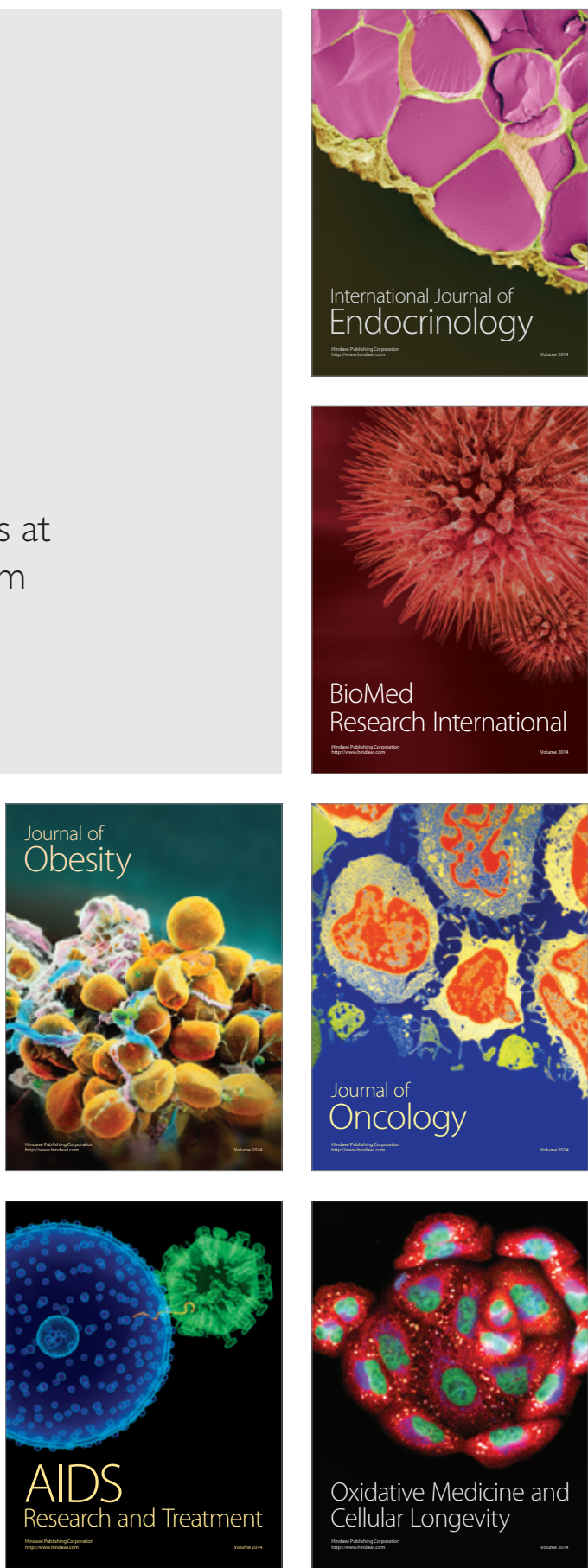